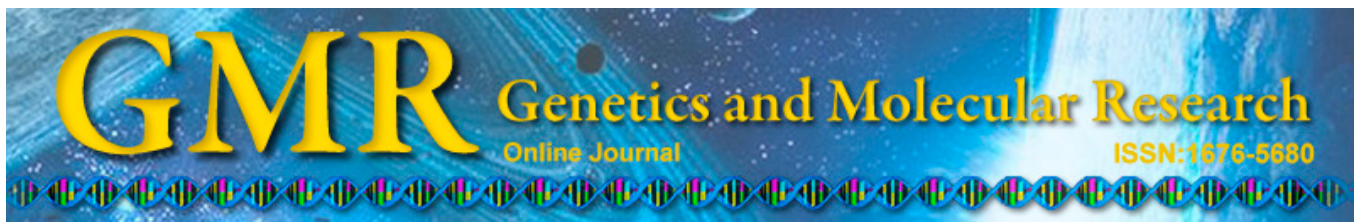

\title{
Therapeutic potential of mesenchymal stem cells to treat Achilles tendon injuries
}

\author{
M.H.C. Vieira ${ }^{1,2 *}$, R.J. Oliveira ${ }^{1,2,3 *}$, L.P.M. Eça ${ }^{4,5}$, I.S.O. Pereira ${ }^{4,5}$, \\ L.C. Hermeto ${ }^{1,6}$, R. Matuo ${ }^{1,3}$, W.S. Fernandes ${ }^{7}$, R.A. Silva ${ }^{1}$ and \\ A.C.M.B. Antoniolli ${ }^{1,2}$
}

${ }^{1}$ Centro de Estudos em Células-Tronco, Terapia Celular e Genética Toxicológica, Núcleo de Hospital Universitário, Universidade Federal de Mato Grosso do Sul, Campo Grande, MS, Brasil

${ }^{2}$ Programa de Pós-graduação em Saúde e Desenvolvimento na Região CentroOeste, Faculdade de Medicina "Dr. Hélio Mandetta",

Universidade Federal de Mato Grosso do Sul, Campo Grande, MS, Brasil

${ }^{3}$ Programa de Mestrado em Farmácia, Centro de Ciências Biológicas, Universidade Federal de Mato Grosso do Sul, Campo Grande, MS, Brasil ${ }^{4}$ Instituto de Pesquisas de Células-Tronco, São Paulo, SP, Brasil ${ }^{5}$ Centro de Atualização em Saúde, São Paulo, SP, Brasil

${ }^{6}$ Programa de Pós-graduação em Cirurgia Veterinária, Faculdade de Ciências Agrárias e Veterinária,

Universidade Estadual Paulista "Júlio de Mesquita Filho", Jaboticabal, SP, Brasil ${ }^{7}$ Centro de Ciências Biológicas, Universidade Federal de Mato Grosso do Sul, Campo Grande, MS, Brasil

*Theses authors contributed equally to this study.

Corresponding author: A.C.M.B. Antoniolli

E-mail: andreia@corporesanosaude.com.br

Genet. Mol. Res. 13 (4): 10434-10449 (2014)

Received July 17, 2014

Accepted November 6, 2014

Published December 12, 2014

DOI http://dx.doi.org/10.4238/2014.December.12.5

ABSTRACT. Rupture of the Achilles tendon diminishes quality of life. The gold-standard therapy is a surgical suture, but this presents complications, including wound formation and inflammation. These complications spurred evaluation of the therapeutic potential of 
mesenchymal stem cells (MSCs) from adipose tissue. New Zealand rabbits were divided into 6 groups (three treatments with two time points each) evaluated at either 14 or 28 days after surgery: cross section of the Achilles tendon (CSAT); CSAT + Suture; and CSAT + MSC. A comparison between all groups at both time points showed a statistically significant increase in capillaries and in the structural organization of collagen in the healed tendon in the CSAT + Suture and CSAT + MSC groups at the 14-day assessment. Comparison between the two time points within the same group showed a statistically significant decrease in the inflammatory process and an increase in the structural organization of collagen in the CSAT and CSAT + MSC groups. A study of the genomic integrity of the cells suggested a linear correlation between an increase of injuries and culture time. Thus, MSC transplantation is a good alternative for treatment of Achilles tendon ruptures because it may be conducted without surgery and tendon suture and, therefore, has no risk of adverse effects resulting from the surgical wound or inflammation caused by nonabsorbable sutures. Furthermore, this alternative treatment exhibits a better capacity for wound healing and maintaining the original tendon architecture, depending on the arrangement of the collagen fibers, and has important therapeutic potential.

Key words: Musculoskeletal system; Achilles tendon; Calcaneal tendon; Cell therapy; Wound healing; Genomic integrity

\section{INTRODUCTION}

The Achilles tendon, which is formed by coalescing fibers of the gastrocnemius and soleus muscles, is fixed at the knee and ankle joints. Given those two connections, and because it is subjected to forces of up to 10 times the body weight, the Achilles tendon is at risk of rupture (Burdett, 1982; Clain and Baxter, 1992) that usually occurs at 2 to $6 \mathrm{~cm}$ from the calcaneal insertion (Carr and Norris, 1989). Such ruptures are acute injuries with mainly extrinsic causal factors and are generally associated with degenerative tendinopathy, which is characterized by the presence of lipid cells, mucoid degeneration, tendon calcification, or a combination of the above (Vailas et al., 1978; Rosenbaum et al., 2010).

Achilles tendon ruptures are common injuries in patients from 30 to 55 years of age and represent $35 \%$ of all tendon injuries, including more than $75 \%$ of those occurring during participation in sports activities (Beskin et al., 1987; Józsa et al., 1989). The annual incidence is 18 to 37 cases per 100,000 individuals, and they commonly result from indirect injuries caused by mechanisms that include forcible traction of the foot with the knee in extension and a sudden and unexpected dorsiflexion of the ankle or violent dorsiflexion with the foot in plantar flexion. The mechanism of acceleration and deceleration is reported as the cause in more than $90 \%$ of sports-related injuries to the Achilles tendon (Soldatis et al., 1997). Additional factors implicated in ruptures include repetitive microtraumas, hypoxia and mucoid degeneration, and a decrease in perfusion resulting from degenerative changes and systemic administration or local infiltration of corticosteroids (Fox et al., 1975; Kannus and Józsa, 1991; Mahler and Fritschy, 1992; Soldatis et al., 1997). 
The non-surgical treatment of Achilles tendon ruptures is associated with a risk of recurrence ranging from 13 to $30 \%$, and with leg muscle atrophy. Nevertheless, non-surgical treatment has the advantage of a lack of surgical wound complications. Surgical treatment results in a lower percentage of re-rupture (0-6\%), early mobilization, and a faster return to sports activity. However, the reported risk of surgical wound complications varies from 0 to 21\% (Mortensen and Pedersen, 1990; Jaakkola et al., 2001; Khan et al., 2005).

The healed tendon tissue shows high cell density and decreased collagen organization, which might explain the high rates of re-rupture, restrictive adhesions, and low tendon function after treatment for tendon lacerations (Józsa and Kannus, 1997; Morberg et al., 1997), which prompts the search for methods capable of modulating a regeneration process that best preserves the original architecture of the tendon. Accordingly, studies use tissue engineering, transplantation of mesenchymal stem cells, and the administration of growth factors (vascular endothelial growth factor 165, basic fibroblast growth factor, recombinant platelet-derived growth factor, and growth differentiation factor 5) as alternative methods to surgical and/or non-surgical conventional treatments (Foland et al., 1992; Gift et al., 1992; Murphy and Nixon, 1997). In this context, the aim of the present study was to evaluate the therapeutic potential of mesenchymal stem cells (MSCs) in the treatment of cross sections of the Achilles tendon.

\section{MATERIAL AND METHODS}

\section{Experiment 1}

\section{Experimental design}

Thirty adult male New Zealand rabbits with an average weight of $2.5 \mathrm{~kg}$ were used. The animals were housed individually in cages, the floors of which were covered with autoclaved wood shavings that were changed weekly, with the lowest possible level of freedom of movement. Commercial feed (Ração Comercial Guabi; Campinas, SP, Brazil) and water were provided ad libitum. The experiment was conducted according to the guidelines of the Universal Declaration on Animal Welfare and with approval from the Ethics Committee on Animal Use of the Universidade Federal de Mato Grosso do Sul (UFMS; protocol No. 307/2011). The animals were randomly divided into 6 experimental groups $(\mathrm{N}=5)$ :

Groups 1 and 2 - A cross section of the Achilles tendon (CSAT) was conducted, which was followed by layered suture, local dressing, and preparation of a long leg plaster cast. Groups 1 and 2 were euthanized for the collection of biological materials at 14 and 28 days, respectively, after the tendon rupture.

Groups 3 and 4 - CSAT + Suture - A CSAT was conducted, which was followed by its suture. Subsequently, a layered suture, local dressing, and preparation of a long leg plaster cast were performed. Groups 3 and 4 were euthanized for the collection of biological materials at 14 and 28 days, respectively, after the tendon rupture.

Groups 5 and 6 - CSAT + MSC - A CSAT was conducted, which was followed by the transplantation of MSCs. Subsequently, a layered suture, local dressing, and preparation of a long leg plaster cast were performed. Groups 5 and 6 were euthanized for the collection of biological materials at 14 and 28 days, respectively, after the tendon rupture. 


\section{Anesthetic procedure}

The animals were anesthetized using ketamine (Rhobifarma Indústria Farmacêutica LTDA) and xylazine (Rhobifarma Indústria Farmacêutica LTDA) at doses of $50 \mathrm{mg} / \mathrm{kg}$ and $10 \mathrm{mg} / \mathrm{kg}$ body weight (b.w.), respectively, that were administered intramuscularly, and the tendon injury was treated with a dose of $5 \mathrm{mg} / \mathrm{kg}$ b.w. morphine (Cristália Produtos Químicos Farmacêuticos LTDA) subcutaneously for the collection of adipose tissue and to perform the injury to the Achilles tendon.

\section{Collection of adipose tissue}

Following sterilization and antisepsis in a surgical environment, epilation and a 2-cm longitudinal surgical incision using a scalpel blade (No. 24) were performed on the dorsal line above the point of greatest accumulation of adipose tissue, approximately $5 \mathrm{~cm}$ from the occiput, in the craniocaudal direction. After exposing the subcutaneous cellular tissue, a $1-\mathrm{cm}^{3}$ fragment was removed via clamping, traction, and sectioning using Metzenbaum scissors. Subsequently, the skin was sutured using nylon thread No. 4-0 (Mononylon) and local dressing. A sample of $1 \mathrm{~cm}^{3}$ adipose tissue was removed during the lipectomy procedure and extensively washed in sterilized phosphate buffer solution (PBS; LGC Biotecnologia) supplemented with $1 \%$ penicillin/streptomycin (1\% PBS, LGC Biotecnologia) for removal of excess blood. The material collected was stored at $4^{\circ} \mathrm{C}$ for up to $24 \mathrm{~h}$ before the explantation of the MSCs.

\section{CSAT}

Following sterilization and antisepsis in a surgical environment, epilation and a lateral longitudinal incision of the right Achilles tendon of the animal, of approximately $1.5 \mathrm{~cm}$, were conducted using a scalpel blade (No. 24) for exposure of the tendon. Then, a tenotomy, i.e., a CSAT, was performed at $10 \mathrm{~mm}$ from its insertion on the calcaneus using straight iris scissors (Figure 1).
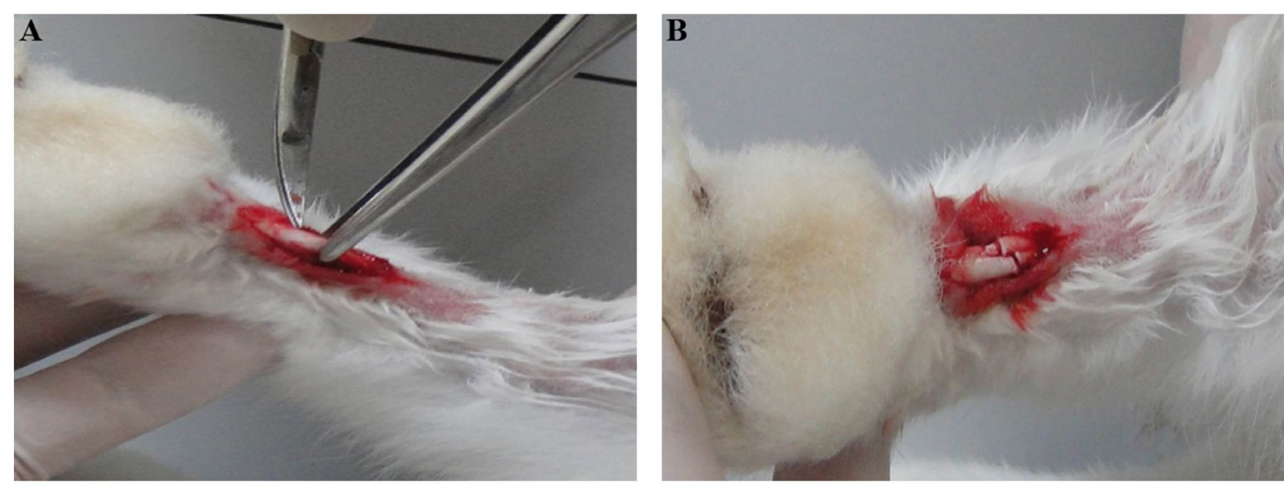

Figure 1. A. Skin incision and exposure of the Achilles tendon. B. Cross section of the Achilles tendon.

\section{Achilles tendon suture}

The suture of the CSAT was performed according to the Kessler technique modified 
by Mason and Allen (1941) (Figure 2) using nylon thread 3-0 (Mononylon) for suturing the tendon and 4-0 (Mononylon) for suturing the paratendon.
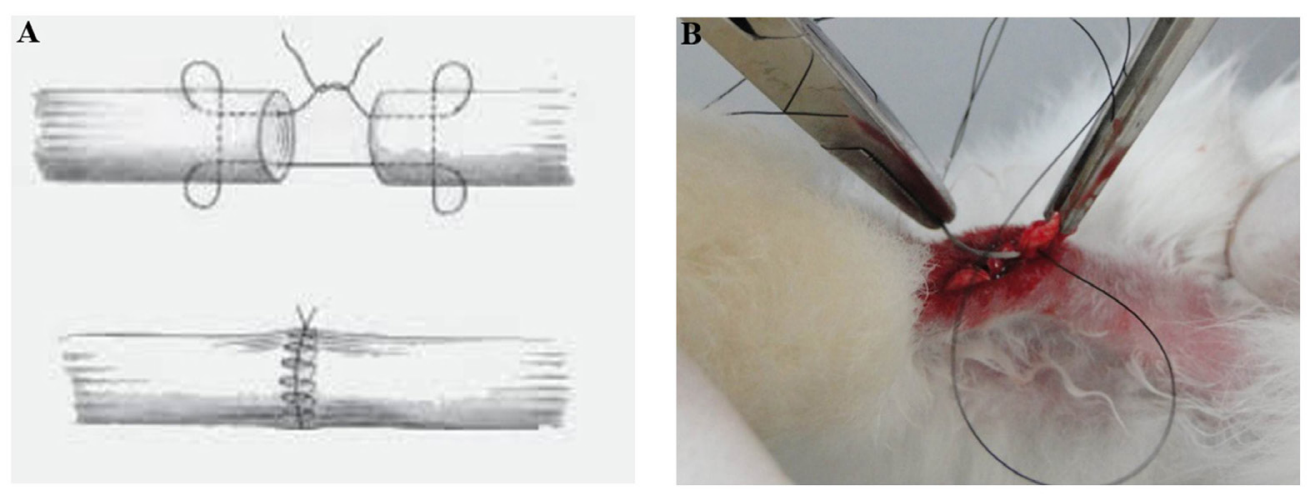

Figure 2. A. Suture layout of the cross section of the Achilles tendon according to the Kessler technique modified by Masson and Allen (1940). B. Photograph illustrating the suture of the Achilles tendon according to the Kessler technique modified by Masson and Allen (1940).

\section{Isolation of MSCs}

The tissue culture procedures were conducted at Instituto de Pesquisas de CélulasTronco (IPCTRON), Centro de Atualização em Saúde (CAS), São Paulo, Brazil. The product of the block lipectomy, which was $1 \mathrm{~cm}^{3}$, was used for the isolation of the MSCs. The adipose tissue was sectioned into fragments of approximately $0.1 \mathrm{~cm}^{3}$, using ophthalmic micro scissors, on a Petri dish containing $3 \mathrm{~mL} \mathrm{1 \%} \mathrm{PBS} \mathrm{to} \mathrm{increase} \mathrm{the} \mathrm{contact} \mathrm{surface.} \mathrm{Then,} \mathrm{the}$ fragments were washed 6 times in $3 \mathrm{~mL} \mathrm{1 \%}$ PBS in beakers by manual rotary movement with moderate force. Subsequently, the fragments were placed on Petri dishes containing 10 $\mathrm{mL}$ low-glucose Dulbecco's modified Eagle's medium (DMEM; LGC Biotecnologia) supplemented with $1 \%$ penicillin/streptomycin (1\% DMEM) for $5 \mathrm{~min}$. Then, the fragments were incubated with HyQtase (LGC Biotecnologia) for $20 \mathrm{~min}$ in a water bath at $37^{\circ} \mathrm{C}$ and stirred every $5 \mathrm{~min}$ with manual rotary movements for $1 \mathrm{~min}$. The suspension was centrifuged for $10 \mathrm{~min}$ at $2000 \mathrm{rpm}$. Then, the supernatant was discarded and the cell pellet was resuspended in 1\% PBS. Next, $3 \mathrm{~mL} \mathrm{1 \%}$ PBS was added and centrifuged at $2000 \mathrm{rpm}$ for $5 \mathrm{~min}$, with the supernatant subsequently discarded and the pellet resuspended again in 1\% PBS. This procedure was conducted in triplicate. The cell pellet preparation was resuspended in $510 \mu \mathrm{L} 1 \%$ DMEM. A $10-\mu \mathrm{L}$ aliquot was collected to determine the cell concentration and viability in a Neubauer chamber. Trypan Blue (LGC Biotecnologia) was used for the analysis of cell viability at a ratio of $1: 1$. A concentration of $2.5 \times 10^{5}$ cells was seeded in tissue culture flasks.

\section{Culture and clonal expansion of MSCs}

MSCs were seeded at a concentration of $2.5 \times 10^{5}$ cells in $25-\mathrm{cm}^{3}$ culture flasks (TTP, Switzerland) containing $5 \mathrm{~mL}$ low-glucose DMEM supplemented with $10 \%$ fetal bovine serum and $1 \%$ penicillin/streptomycin (DMEMsupl), and kept in a $\mathrm{CO}_{2}$ incubator at $37^{\circ} \mathrm{C}$ and $5 \% \mathrm{CO}_{2}$. DMEMsupl was changed every $48 \mathrm{~h}$ and the first two media changes were preceded by washing with $3 \mathrm{~mL}$ PBS to remove cell and tissue debris. The culture medium was dis- 
carded upon reaching growth of approximately $70 \%$ confluence, and the cultures were washed 3 times with $3 \mathrm{~mL}$ PBS. Then, $1 \mathrm{~mL} 0.25 \%$ trypsin (LGC Biotecnologia) was added, and the flasks were incubated for $2-3 \mathrm{~min}$ at $37^{\circ} \mathrm{C}$. After detachment of the cells, $10 \mathrm{~mL}$ DMEMsupl was added. Then, the culture medium was transferred into a sterilized conical tube and centrifuged at $2000 \mathrm{rpm}$ for $5 \mathrm{~min}$. The pellet was resuspended in $510 \mu \mathrm{L}$ DMEMsupl. A 10- $\mu \mathrm{L}$ aliquot was collected to assess the cell concentration and viability, as described above. Cultures with cell viability above $95 \%$ were seeded in $25-\mathrm{cm}^{3}$ cell culture flasks, thus promoting clonal expansion.

\section{Transplantation of MSCs}

Second-passage cells were used for the autologous transplantation in loco of MSC, which was performed immediately after the tenotomy, at the concentration of $1.0 \times 10^{6}$ cells in a final volume of $0.1 \mathrm{~mL}$ by insulin syringe with a $13 \times 4.5-\mathrm{mm}$ needle. Then, the skin was sutured with simple stitches using 4-0 nylon thread (Mononylon) and local dressing, and the preparation of a long leg plaster cast was performed.

\section{Immobilization by long leg plaster cast}

Number 6 casts (Cremer) were prepared according to manufacturer instructions. All animals were immobilized with the long leg plaster cast, maintaining the operated ankle in the equine position.

The control of the tendon stump suturing was performed by palpation and negative identification of spacing between them in the CSAT and CSAT + MSC groups prior to the application of the long leg plaster cast.

\section{Histological evaluation}

The animals were euthanized by intraperitoneal injection of pentobarbital $(100 \mathrm{mg} / \mathrm{kg}$ b.w.) at the end of the experimental period. The operated hind legs were dissected, preserving the integrity of the Achilles tendon, from which a fragment with a $10-\mathrm{mm}$ margin proximal and distal to the cross-sectional site was removed. That fragment was fixed in $4 \%$ formaldehyde for 5 days, processed, embedded in paraffin, sectioned crosswise (5- $\mu \mathrm{m}$ thickness), and stained using routine histological methods, as follows: (I) hematoxylin-eosin for studying the vascularization and proliferation of fibroblasts at the level of the tendon; and (II) Gömöri trichrome for studying collagen type I. The slides were submitted for histological evaluation in a double-blind system under bright-field microscopy. Ordinal variables are expressed as scores, whose equivalences are shown in Table 1.

\section{Statistical analysis}

The Mann-Whitney test was used to compare the mean scores in each group between time points (14 days versus 18 days). The Kruskal-Wallis test was used for the comparison between groups (CSAT versus CSAT + Suture versus CSAT + MSC) at the assessed time points (14 or 28 days). The level of significance adopted was $\mathrm{P}<0.05$. 
Table 1. Classification of histological findings reported at the site of the cross section of the Achilles tendon.

\begin{tabular}{|c|c|c|c|}
\hline \multicolumn{2}{|l|}{ Histological findings } & \multirow{2}{*}{$\begin{array}{l}\text { Classification } \\
\text { Absence }\end{array}$} & \multirow{2}{*}{$\frac{\text { Score }}{0}$} \\
\hline \multirow{5}{*}{ Inflammatory process } & & & \\
\hline & + & 1 focus & 1 \\
\hline & ++ & 2 collections of lymphocytes and histiocytes with presence of lymphoid follicles & 2 \\
\hline & +++ & Diffuse inflammatory process & 3 \\
\hline & & Absence & 0 \\
\hline \multirow{4}{*}{ Adipose tissue } & + & 1 to 2 collections of adipocytes & 1 \\
\hline & ++ & 3 to 5 collections of adipocytes* & 2 \\
\hline & +++ & More than 5 collections of adipocytes* & 3 \\
\hline & & Absence & 0 \\
\hline \multirow[t]{4}{*}{ Capillaries } & + & Up to $5^{*}$ & 1 \\
\hline & ++ & From 5 to $10^{*}$ & 2 \\
\hline & +++ & More than $10^{*}$ & 3 \\
\hline & & Absence & 0 \\
\hline \multirow[t]{4}{*}{ Arterioles } & + & From 1 to 3 per field** & 1 \\
\hline & ++ & From 3 to 5 per field** & 2 \\
\hline & +++ & More than 5 per field $* *$ & 3 \\
\hline & & Absence & 0 \\
\hline \multirow[t]{3}{*}{ Structural disorganization } & + & Low & 1 \\
\hline & ++ & Moderate & 2 \\
\hline & +++ & High & 3 \\
\hline
\end{tabular}

*40X magnification; $* * 10 \mathrm{X}$ magnification.

\section{Experiment 2}

The samples from two rabbits were used for the development of cell differentiation and the evaluation of the genomic integrity, maintaining the same experimental conditions described for Experiment 1. The experiments were conducted in duplicate.

\section{Adipogenic, osteogenic, and chondrogenic differentiation}

Culture flasks with a capacity of $75 \mathrm{~cm}^{2}$ and at approximately $80 \%$ confluence, which were derived from two different experimental animals, were trypsinized to prepare eight 25$\mathrm{cm}^{2}$ bottles and two $15-\mathrm{mL}$ Falcon tubes. Next, $2 \times 10^{5}$ cells were seeded in the flasks, and 1 $\mathrm{x} 10^{6}$ cells were seeded in the Falcon tubes. Four bottles were used for the comet assay. Two $25-\mathrm{cm}^{2}$ flasks and one Falcon tube were maintained in DMEMsupl throughout the experimental period and thus served as controls for the processes of cell differentiation. The other two culture flasks and one Falcon tube were used in the cell differentiation procedure. The cells were maintained in DMEMsupl for $24 \mathrm{~h}$ during the adipogenic and osteogenic differentiation. Then, the medium was discarded, and the media from the STEMPRO adipogenesis and osteogenesis differentiation kits (Invitrogen, Life Technologies, Carlsbad, CA, USA) were added for 14 consecutive days, with media changes twice a week. The cells were maintained in DMEMsupl for $2 \mathrm{~h}$ for the chondrogenic differentiation. The medium was then discarded following centrifugation for $10 \mathrm{~min}$ at $1200 \mathrm{rpm}$, and the medium from the STEMPRO chondrogenesis differentiation kit (Invitrogen) was added. The cells remained in this media for 21 consecutive days, with medium changes conducted twice a week. Then, the culture media were discarded, and the cells were fixed in $10 \%$ buffered formalin. The Oil Red O, Alizarin Red, and toluidine blue dyes were used for the adipogenic, osteogenic, and chondrogenic differentiation, respectively. 


\section{Evaluation of genomic integrity}

The comet assay was used for evaluating the genomic integrity of MSCs, modified from Oliveira et al. (2007). Culture flasks with a $25-\mathrm{cm}^{2}$ capacity and at approximately $80 \%$ confluence were trypsinized according to the conditions described for Experiment 1 . Then, the cell solutions were centrifuged, and the pellets were resuspended in $0.5 \mathrm{~mL}$ DMEMsupl. A $20.0-\mu \mathrm{L}$ aliquot of cell suspension was mixed with $120.0 \mu \mathrm{L}$ low-melting-point agarose $(0.75 \%)$ at $37^{\circ} \mathrm{C}$ and placed on slides pre-coated with normal agarose $(1.5 \%)$. The slides were covered with a glass coverslip and refrigerated at $4{ }^{\circ} \mathrm{C}$ for $20 \mathrm{~min}$. After removing the coverslips, the slides were immersed in a recently prepared lysis solution consisting of $89.0 \mathrm{~mL}$ lysis stock [2.5 M NaCl, $100.0 \mathrm{mM}$ ethylenediaminetetraacetic acid (EDTA), $10.0 \mathrm{mM}$ Tris, $\mathrm{pH}$ 10.0 adjusted with solid $\mathrm{NaOH}$, and $890.0 \mathrm{~mL}$ distilled water], $1.0 \mathrm{~mL}$ Triton X-100 (Merck), and $10.0 \mathrm{~mL}$ dimethyl sulfoxide. The lysis occurred for $1 \mathrm{~h}$ at $4{ }^{\circ} \mathrm{C}$ in the dark. The slides were then run in an electrophoresis tank with $\mathrm{pH}>13.0$ buffer $(300.0 \mathrm{mM} \mathrm{NaOH}$ and $1.0 \mathrm{mM}$ EDTA, prepared from a stock solution of $10.0 \mathrm{~N} \mathrm{NaOH}$ and $200.0 \mathrm{mM}$ EDTA, $\mathrm{pH} 10.0$ ) at $4^{\circ} \mathrm{C}$ for $20 \mathrm{~min}$ for DNA denaturation. The electrophoresis was conducted at $25.0 \mathrm{~V}$ and 300.0 $\mathrm{mA}(1.25 \mathrm{~V} / \mathrm{cm})$. Subsequently, the slides were neutralized using $0.4 \mathrm{M}$ Tris-HCl buffer, $\mathrm{pH}$ 7.5 , for 3 cycles of $5 \mathrm{~min}$, air dried, fixed in absolute ethyl alcohol for $10 \mathrm{~min}$, and stored for subsequent reading. The slides were stained using $100 \mu \mathrm{L}$ SYBR green $(1: 10,000)$ dye for the analysis of the comet assays. The material was evaluated under a fluorescence microscope (Nikon, Japan) at 40X magnification. Fifty cells were counted per slide, which were evaluated using the Comet Assay IV software (Perceptive Instruments Ltd, United Kingdom). The statistical analysis was conducted using the Student $t$-test $(\mathrm{P}<0.05)$.

\section{RESULTS}

\section{Experiment 1}

The cell viability of the cultures used in Experiment 1 ranged from 95 to $98 \%$. Table 2 shows the data regarding the histological analysis.

The evaluation of the inflammatory process (Figure 3A and B) showed that there was no difference between the groups for both time points assessed (14 and 28 days, $\mathrm{P}>0.05$ ). However, the inflammatory process decreased from the first (14 days) to the second time point (28 days) of assessment within the CSAT and CSAT + MSC groups.

No statistically significant differences $(\mathrm{P}<0.05)$ regarding metaplasia, marked by the presence of adipose tissue, chondroid tissue, and mucin, occurred between the groups or within the same group when comparing both time points.

Statistically significant differences $(\mathrm{P}<0.05)$ regarding the development of capillaries and arterioles occurred between the groups only at the first time point (14 days). An increase ( $\mathrm{P}$ $<0.05)$ in capillaries was recorded in the CSAT + Suture and CSAT + MSC groups, compared with the CSAT group. A significant increase $(\mathrm{P}<0.05)$ in arterioles was noted in the CSAT + Suture group compared with the other two groups (CSAT and CSAT + MSC). No statistically significant differences $(\mathrm{P}>0.05)$ were found for the second time point $(28$ days) and/or when comparing both time points within the groups.

An evaluation of the structural organization showed that statistically significant differences $(\mathrm{P}<0.05)$ occurred between the groups. A statistically significant increase $(\mathrm{P}<0.05)$ in 
the structural organization of the CSAT + Suture and CSAT + MSC groups was noted (Figure 3C) in comparison to the CSAT group (Figure 3D) when evaluating the first time point (14 days). Although no statistically significant differences occurred, a greater trend towards an increased structural organization was observed for the CSAT+ MSC group. Moreover, a statistically significant increase $(\mathrm{P}<0.05)$ in the CSAT and CSAT + MSC groups occurred when comparing the structural organization within the same group for both time points.

\begin{tabular}{|c|c|c|c|c|}
\hline \multirow[t]{2}{*}{ Variable } & CSAT & CSAT + Suture & STTA + MSC & $\mathrm{P}^{(1)}$ \\
\hline & Means \pm SD & Means \pm SD & Means \pm SD & \\
\hline \multicolumn{5}{|c|}{ Inflammatory process } \\
\hline 14 days & $1.3 \pm 0.5^{\mathrm{a}}$ & $1.3 \pm 0.6^{\mathrm{a}}$ & $1.4 \pm 0.5^{\mathrm{a}}$ & 0.902 \\
\hline 28 days & $0.0 \pm 0.0^{\mathrm{a} *}$ & $0.6 \pm 0.5^{\mathrm{a}}$ & $0.2 \pm 0.4^{\mathrm{a} *}$ & 0.230 \\
\hline$P^{(2)}$ & 0.011 & 0.100 & 0.014 & \\
\hline \multicolumn{5}{|c|}{ Adipose tissue } \\
\hline 14 days & $1.5 \pm 0.6^{\mathrm{a}}$ & $1.7 \pm 0.6^{\mathrm{a}}$ & $1.0 \pm 0.7^{\mathrm{a}}$ & 0.328 \\
\hline 28 days & $0.8 \pm 0.1^{\mathrm{a}}$ & $1.0 \pm 1.0^{\mathrm{a}}$ & $0.7 \pm 1.2^{\mathrm{a}}$ & 0.800 \\
\hline $\mathrm{P}^{(2)}$ & 0.286 & 0.273 & 0.315 & \\
\hline \multicolumn{5}{|l|}{ Capillaries } \\
\hline 14 days & $2.0 \pm 0.0^{\mathrm{a}}$ & $3.0 \pm 0.0^{\mathrm{b}}$ & $3.0 \pm 0.0^{\mathrm{b}}$ & 0.004 \\
\hline 28 days & $2.0 \pm 0.0^{\mathrm{a}}$ & $2.4 \pm 0.5^{\mathrm{a}}$ & $2.7 \pm 0.5^{\mathrm{a}}$ & 0.062 \\
\hline $\mathrm{P}^{(2)}$ & 1.000 & 0.100 & 0.361 & \\
\hline \multicolumn{5}{|l|}{ Arterioles } \\
\hline 14 days & $0.8 \pm 0.5^{\mathrm{a}}$ & $2.0 \pm 0.0^{\mathrm{b}}$ & $1.0 \pm 0.0^{\mathrm{a}}$ & 0.009 \\
\hline 28 days & $1.0 \pm 0.0^{\mathrm{a}}$ & $1.6 \pm 0.5^{\mathrm{a}}$ & $1.2 \pm 0.4^{\mathrm{a}}$ & 0.068 \\
\hline $\mathrm{P}^{(2)}$ & 0.522 & 0.273 & 0.648 & \\
\hline \multicolumn{5}{|c|}{ Structural disorganization } \\
\hline 14 days & $3.0 \pm 0.0^{\mathrm{a}}$ & $2.3 \pm 0.6^{\mathrm{b}}$ & $2.0 \pm 0.0^{\mathrm{b}}$ & 0.014 \\
\hline 28 days & $2.0 \pm 0.6^{\mathrm{a} *}$ & $1.6 \pm 0.5^{\mathrm{a}}$ & $1.2 \pm 0.4^{\mathrm{a} *}$ & 0.064 \\
\hline $\mathrm{P}^{(2)}$ & 0.033 & 0.100 & 0.022 & \\
\hline \multicolumn{5}{|c|}{ Chondroid tissue } \\
\hline 14 days & $0.0 \pm 0.0$ & $0.0 \pm 0.0$ & $0.0 \pm 0.0$ & - \\
\hline 28 days & $0.0 \pm 0.0$ & $0.0 \pm 0.0$ & $0.0 \pm 0.0$ & - \\
\hline$P$ & - & - & - & \\
\hline \multicolumn{5}{|l|}{ Mucin } \\
\hline 14 days & $0.0 \pm 0.0$ & $0.0 \pm 0.0$ & $0.0 \pm 0.0$ & - \\
\hline 28 days & $0.0 \pm 0.0$ & $0.0 \pm 0.0$ & $0.0 \pm 0.0$ & - \\
\hline $\mathrm{P}$ & - & - & - & \\
\hline
\end{tabular}

(1)Kruskal-Wallis test. Different letters indicate statistically significant differences. ${ }^{(2)}$ Mann-Whitney test (comparison between the 14th and the 28th day).*Statistically significant difference. Superscript letters should not be considered (if present) because they refer to the Kruskal-Wallis test. $\mathrm{SD}=$ standard deviation.

\section{Experiment 2}

The cell viability of the cultures used in Experiment 2, ranging from 94 to $99 \%$ with a mean of $96.00 \pm 1.08$, are shown in Figure 4A.

Figure 4B shows the mean \pm standard error values for the genomic integrity of the MSCs in the first and second passages, as evaluated by tail intensity. The values recorded were $38.27 \pm 4.00$ and $60.35 \pm 3.78$, showing a 1.58 -fold increase from the first to the second passage, respectively. Figure $4 \mathrm{C}$ shows the mean \pm standard error values for the tail length, with no statistically significant differences. The values recorded were $0.37 \pm 0.03$ and $0.42 \pm 0.03$ for the first and second passages, respectively.

The processes of adipogenic, osteogenic, and chondrogenic differentiation were adequate and showed that the cultured cells may produce the respective tissues, which demonstrates a characteristic feature of MSCs (Figure 5A-F). 

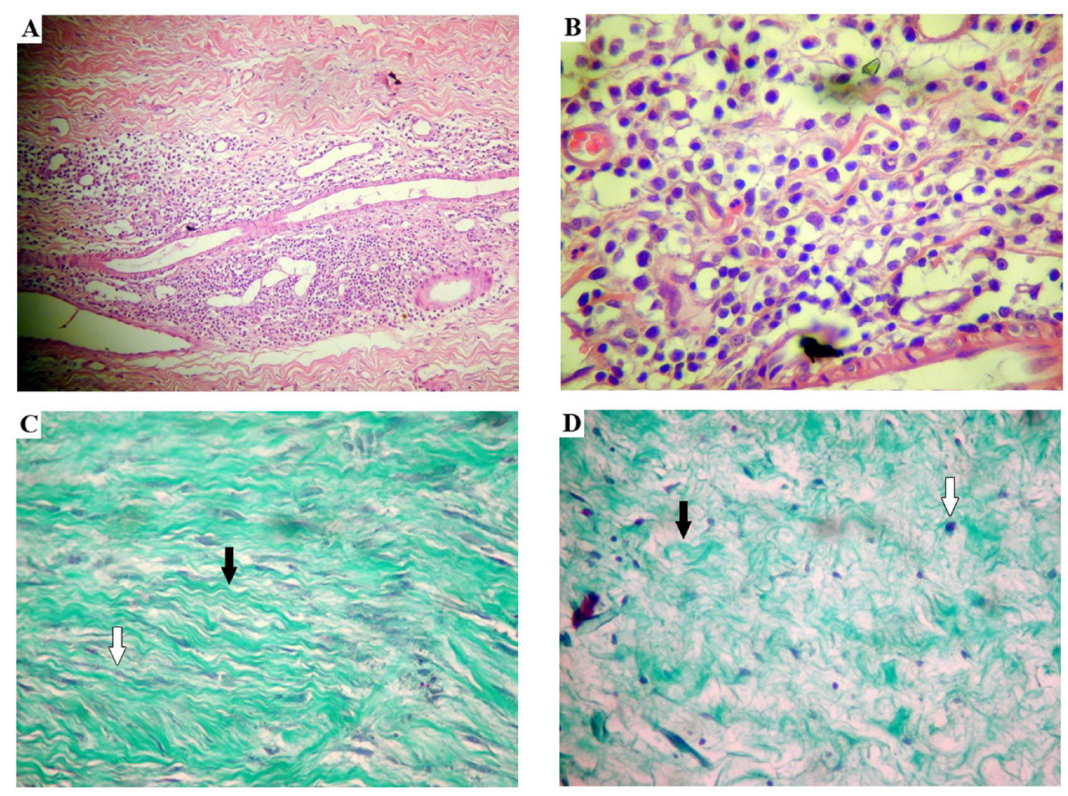

Figure 3. Photomicrographs of hematoxylin-eosin staining. Inflammatory process. The CSAT + Suture group at 14 days at (A) 100X magnification and (B) 400X magnification. C. A photomicrograph of Gömöri trichrome staining. Type I (black arrow) and type III (white arrow) collagen fibers (400X magnification). The CSAT + MSC group at 14 days, showing organized collagen fibers. D. A photomicrograph of Gömöri trichrome staining. Type I (black arrow) and type III (white arrow) collagen fibers (400X magnification). The CSAT group at 14 days, showing disorganized collagen fibers.

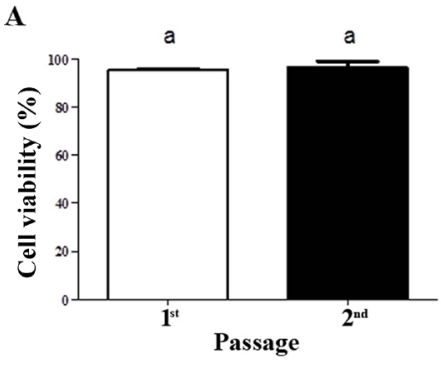

C

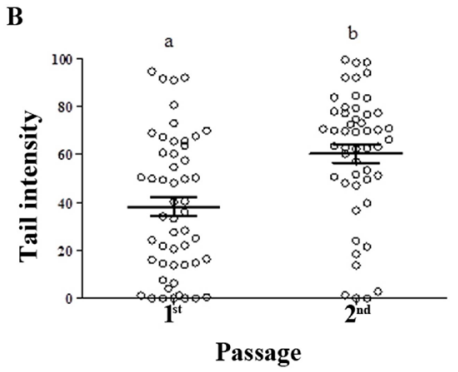

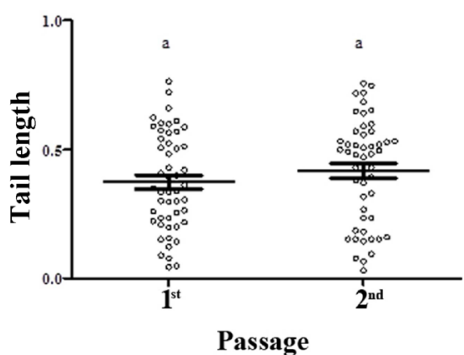

Figure 4. A. Cell viability. B. Comet tail intensity in the genomic integrity assay. C. Comet tail length in the genomic integrity assay. 

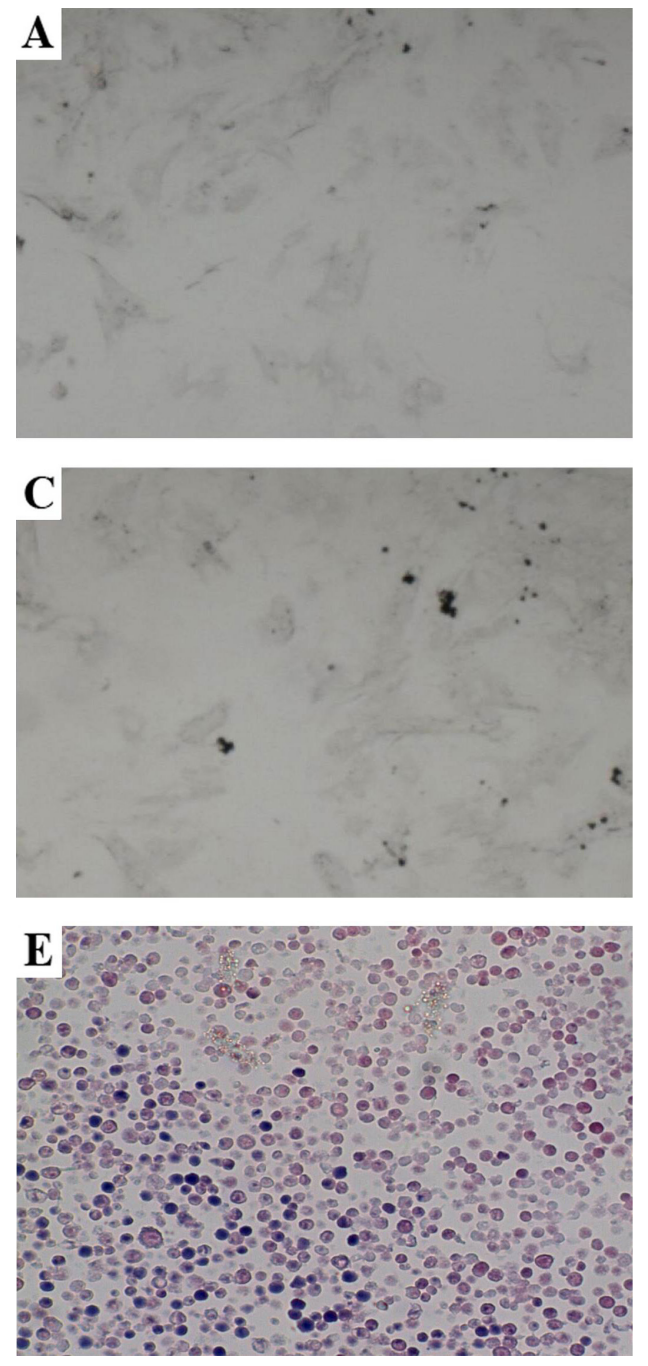
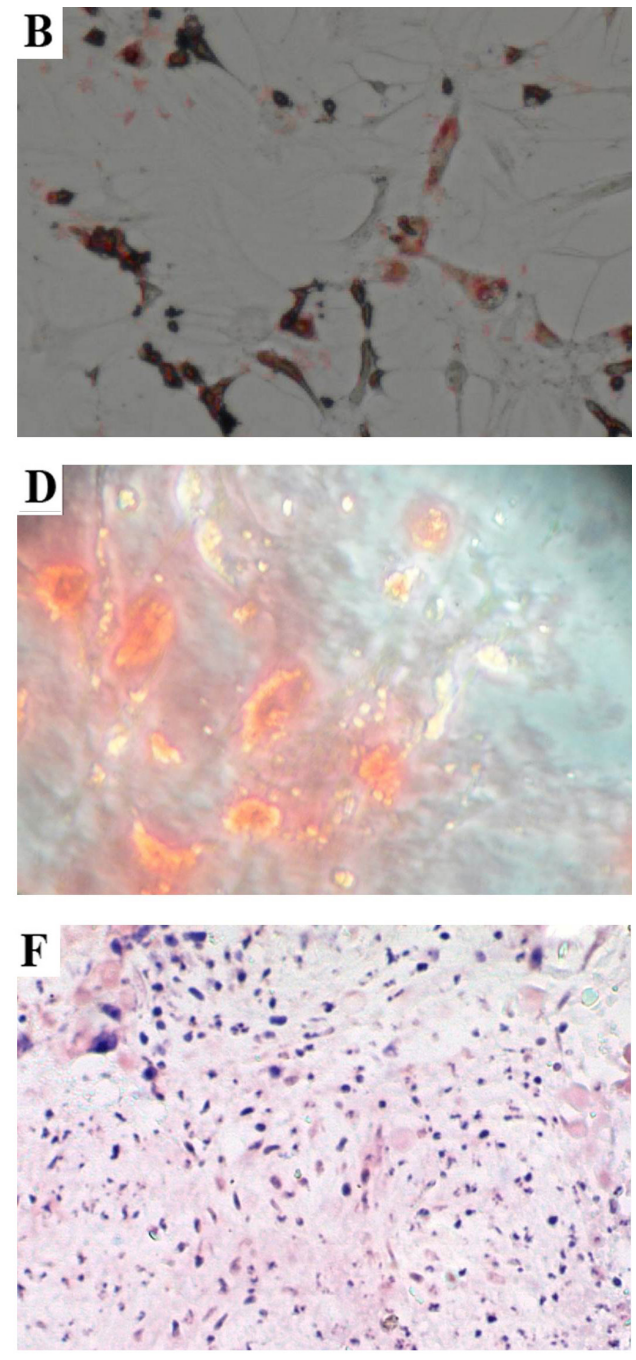

Figure 5. Cell differentiation. A. Control of osteogenic differentiation (monolayer growth); B. osteogenic differentiation; C. control of adipogenic differentiation (monolayer growth); D. adipogenic differentiation; E. control of chondrogenic differentiation (three-dimensional culture); F. chondrogenic differentiation.

\section{DISCUSSION}

The quality of life of many patients, particularly athletes, may be diminished by rupture of the Achilles tendon. In addition to the trauma, other diseases may affect the tendon, which leads to a loss of muscle function and significant disability if left untreated (Thien et al., 2004). However, both surgical and non-surgical treatments have complications (Mortensen and Pedersen, 1990; Jaakkola et al., 2001; Khan et al., 2005); a key issue is the inability of the tendon to self-regenerate to preserve the original architecture because of the high cell density and low collagen organization, which are related to high rates of re-rupture (Józsa and Kannus, 
1997; Morberg et al., 1997). Thus, methods that improve the efficiency of the regenerative process are of great interest to the field, and studies show that the use of MSCs may be a good strategy to improve the regeneration of the sutured tendons (Rosenbaum et al., 2010; Daher et al., 2011). However, no study in the literature consulted evaluated sectioned and non-sutured tendons. This lack motivated the current novel study, which used MSC transplantation in rabbits subjected to a CSAT with subsequent immobilization in a long leg plaster cast.

Although ruptures of the Achilles tendon usually result from previous tendinopathy, and frayed fibers are detected by macroscopic observation, the main experimental model that was used in other studies, and also in this study, involves a tendon cross section at $10 \mathrm{~mm}$ from its insertion in the calcaneus, which is the site corresponding to the area most resistant to tensile forces (Chong et al., 2007; Daher et al., 2011).

Rehabilitation following tendon injury and repair is a process that usually requires weeks. During this period, immobilization and movement protection are necessary (Kvist, 1994). However, that restriction exposes the patient to risks, including adhesions and poor quality repair, and the biomechanical and mechanical properties of the healed tendons never reach those of intact tendons (Winter et al., 1998). However, Gossman et al. (1986) evaluated the elongation and circumference of the soleus and plantar muscles of rabbits following a cast immobilization and noted that no change occurred in either muscle when the muscle was immobilized in the extended position. Notwithstanding those facts, a long leg plaster cast and maintenance of muscle shortening to bring together the proximal and distal stumps of the nonsutured tendon were the choice in the present study.

Studies on tendon healing showed that the exudation and fibrous union phase begins around the fifth postoperative day, which is when the tensile force is still small. The fibroplasia phase starts from the fifth postoperative day, and the tensile force begins to increase, reaching stabilization around the 14th to the 16th postoperative day, a phase in which tenorrhaphy still relies heavily on the suture thread. The maturation, organization, and differentiation phase starts from that period onward, and the tensile force will gradually increase over an indefinite time period (Carlstedt and Skagervall, 1986; O'Broin et al., 1995). Therefore, those facts motivated the evaluation at the beginning of the critical healing phase (14th postoperative day) and at a later period (28th postoperative day).

The histological analysis indicated that the inflammatory process showed no differences between the groups at the two time points assessed. However, a reduction of the inflammatory process from the 14th to the 28th postoperative day was noted in the CSAT and CSAT + MSC groups, when comparing within the same group. This suggests that the suture may trigger or lengthen the duration of inflammation. According to Karjalainen et al. (2010), in addition to the suture, the type of suture thread and technique used may increase the tissue damage and thus be associated with more severe and/or prolonged inflammatory processes. Furthermore, nonabsorbable sutures have the disadvantage of promoting the formation of foreign body granuloma, according to Manson and Allen (1941). However, nonabsorbable monofilament sutures, such as those used in this study, are commonly used in tendon repair because they last for a long time without losing the traction force required during the tendon healing period that usually extends into the fourth or fifth postoperative weeks (Carlstedt and Skagervall, 1986).

The vascularization score was increased in the CSAT + Suture and CSAT + MSC groups. This finding is corroborated by the study by Okamoto et al. (2010), who reported that MSCs promote the release of growth factors and cytokines, thus increasing local vasculariza- 
tion in addition to acting as an extrinsic factor for tendon healing. Moreover, the suture also increases vascularization, given its foreign body reaction (Manson and Allen, 1941).

The group with the lowest structural organization of collagen fibers was CSAT when compared to the CSAT + Suture and CSAT + MSC groups at the 14-day time point. Although no statistically significant differences were observed between the CSAT + Suture and CSAT + MSC groups, a trend toward more organization was observed in the CSAT + MSC group. This inference could also be made from the qualitative evaluation of histological slides. No statistically significant difference was found between the groups evaluated at the 28 -day time point. However, a comparison of both periods within the same groups showed that the increase of structural organization was only statistically significant in the CSAT and CSAT + MSC groups. Therefore, the transplantation of MSCs is presumably more effective than a suture in ensuring a better architecture and collagen fiber organization of the healed tendon throughout the process. However, the finding that statistically significant differences occurred between the CSAT and CSAT + Suture groups on the 14th postoperative day corroborates previous studies (Smith and Evans, 2001; Groth, 2005; Lawrence et al., 2005), which reported that a tendon suture facilitates collagen fiber organization and promotes early mobilization.

Statistically significant differences that were observed only at the first assessment (14th postoperative day) were also reported by Daher et al. (2011). Those authors histologically evaluated the Achilles tendon of rats subjected to rupture, suture, and injection of MSCs at time points of 2, 4, and 6 weeks, and the differences were only observed at the first assessed time point between the rupture and suture groups. Conversely, the second and third assessments of the collagen fiber organization showed no differences from the control group.

The results found in this study encourage the use of stem cells in Achilles tendon healing. A study by Young et al. (1998) showed that the use of MSCs is also promising if the cells are seeded in collagen matrices, which promote tendon repair, thereby corroborating the assertion. The authors noted an improvement in the biomechanics, structure, and function of the tendon in their study. Although no biomechanical evaluation was conducted in the present study, the histology may be correlated to the biomechanics, considering studies such as that by Rosenbaum et al. (2010), who introduced a system of histological grading with three variables, namely collagen organization, angiogenesis, and cartilage formation, and concluded that only the sum of changes found in each of the variables enables correlation with the biomechanical test. Thus, that study enables researchers to attain an estimate of the biomechanical performance with reduced cost. Therefore, based on the histological patterns found in the present study, the experimental animals treated with MSC, followed by the CSAT + Suture group, should show improvements in biomechanical activity compared with the CSAT group because neovascularization and improvement in collagen organization occurred in the former groups; therefore, there was an improvement in the healed tendon irrigation and better maintenance of the original architecture of the tendon.

Given the present results, it must also be emphasized that MSCs may directly participate in the regeneration of injured tissue through two distinct mechanisms: (i) direct contribution through differentiation into phenotypes of tissue-specific cells; and (ii) production of extracellular matrix. Furthermore, reports show that MSCs indirectly contribute to healing through the production of bioactive proteins, including growth factors, anti-apoptotic factors, and chemotactic agents. These secreted proteins have an effect on cellular dynamics, vascular stimulation, and recruitment of additional stem cells that are capable of promoting a greater healing stimulus (Vishnubalaji et al., 2012). 
One broader discussion about stem cell therapy with MSCs and/or other stem cells concerns the degree of safety for patients. A pertinent question is the quality of the genetic material of the cells cultured in vitro for long periods and undergoing clonal expansion. That doubt about quality, which still persists in the literature, motivated the evaluation of the genomic integrity of the cultured MSCs. The same technique developed by Oliveira et al. (2007) was used for that purpose. Direct quantification of damaged DNA in individual cells was first proposed by Rydenberg and Johason in 1987, according to Tice (1995). Later, in 1984, Ostling and Johanson modified the running buffer and started to use it at a semi-neutral $\mathrm{pH}(\mathrm{pH}$ 9.5). However, Singh et al. (1988) proposed electrophoresis in an alkaline buffer $(\mathrm{pH}>13)$ and transformed the comet assay into a key method for detecting DNA breaks and damage in alkali-labile sites in vivo and in vitro. Since then, the comet method has found several applications, which motivated its choice for the evaluation of the genomic integrity of the MSCs in the present study. The frequency of genomic damage in the second passage, when measuring the DNA intensity in the tail, was 1.58 -fold greater than the damage observed in the first passage, according to the data. Initially, that fact would contraindicate the transplantation of MSCs. However, the cell viability of the cultures, which was evaluated using the Trypan Blue method that is extensively used among studies on MSCs (Martin-Piedra et al., 2013, 2014; Reissis et al., 2013), was approximately $96 \%$. Furthermore, no statistically significant differences were observed between the two passages when measuring the tail length. Thus, transplantation was chosen based on those latter two facts. However, new studies assessing whether a buffer with $\mathrm{pH}>13$ is truly the most appropriate version of the comet assay for studies with MSCs and whether the parameter of DNA intensity in the tail is more relevant than tail length must be conducted.

The comparison of the tail length data from the present experiment and the study by Froelich et al. (2013) showed an increase of 139.14-fold in the second passage. That result raises questions about the protocols used; the protocol with $\mathrm{pH}>13$ that was used in the present study should be a more sensitive assay than those using a buffer at $\mathrm{pH} \cong 10$. Two possibilities of using the latter method are evident: (i) $\mathrm{pH} \cong 10$ would be more adequate to study MSCs; or (ii) the culture protocol proposed would be capable of increasing the levels of DNA damage. However, it must be noted that an increase of 1.58 -fold occurred in the tail intensity from one passage to the second in this study, a result that should be considered for a comprehensive evaluation of the process. Furthermore, the origin of the cells must be considered because adipose tissue cells from rabbits were used in the present study, while the other researchers used human cells. Moreover, Froelich et al. (2013) indicated the absence of genotoxicity in longterm cultures. However, they found an increased frequency of mutagenic damage and inferred the possibility of transformation of the MSCs into cells with chromosomal instability and/or malignant potential. These facts underline the need for further studies in the field of genetic toxicology that may predict the safety of MSC therapy and, furthermore, that could be used as a basis to create batteries of tests enabling the screening of potential contraindications of therapeutic transplantation of MSCs in humans. Therefore, these questions still remain. However, the present study also lacks sufficient data to contraindicate MSC therapy, especially given that the cost-benefit ratio was favorable when comparing the histological improvement observed and the reduced chance of developing tumors.

Considering the above-mentioned points, one can conclude that MSC transplantation is a good alternative for the treatment of ruptured Achilles tendons in rabbits. Furthermore, the results of the alternative treatment were better than those related to the use of the gold- 
standard method, i.e., tendon suture, because the latter is associated with an invasive surgical process and has complicating factors, including a surgical wound and inflammation caused by the nonabsorbable sutures. Thus, MSC transplantation has the advantage of avoiding surgery and tendon suture and their risks. Moreover, this method displays a better capacity for wound healing and maintenance of the original tendon architecture, given the arrangement of the collagen fibers, which has important therapeutic potential.

\section{ACKNOWLEDGMENTS}

Research supported by FUNDECT (Edital Chamada FUNDECT \#5/2011 - PPP - Processo \#23/200.702/2012 - Termo de Outorga \#0207/12 and Edital Chamada FUNDECT/ CAPES \#12/2014 - BIOTA-MS Processo \#23/200.225/2014).

\section{Conflicts of interest}

The authors declare no conflict of interest.

\section{REFERENCES}

Beskin JL, Sanders RA, Hunter SC and Hughston JC (1987). Surgical repair of Achilles tendon ruptures. Am. J. Sports Med. 15: 1-8.

Burdett RG (1982). Forces predicted at the ankle during running. Med. Sci. Sports Exerc. 14: 308-316.

Carlstedt CA and Skagervall R (1986). A model for computer-aided analysis of biomechanical properties of the plantaris longus tendon in the rabbit. J. Biomech. 19: 251-256.

Carr AJ and Norris SH (1989). The blood supply of the calcaneal tendon. J. Bone Joint Surg. Br. 71: 100-101.

Chong AK, Ang AD, Goh JC, Hui JH, et al. (2007). Bone marrow-derived mesenchymal stem cells influence early tendonhealing in a rabbit achilles tendon model. J. Bone Joint Surg. Am. 89: 74-81.

Clain MR and Baxter DE (1992). Achilles tendinitis. Foot Ankle 13: 482-487.

Daher RJ, Chahine NO, Razzano P, Patwa SA, et al. (2011). Tendon repair augmented with a novel circulating stem cell population. Int. J. Clin. Exp. Med. 4: 214-219.

Foland JW, Trotter GW, Powers BE, Wrigley RH, et al. (1992). Effect of sodium hyaluronate in collagenase-induced superficial digital flexor tendinitis in horses. Am. J. Vet. Res. 53: 2371-2376.

Fox JM, Blazina ME, Jobe FW, Kerlan RK, et al. (1975). Degeneration and rupture of the Achilles tendon. Clin. Orthop. Relat. Res. 221-224.

Froelich K, Mickler J, Steusloff G, Technau A, et al. (2013). Chromosomal aberrations and deoxyribonucleic acid singlestrand breaks in adipose-derived stem cells during long-term expansion in vitro. Cytotherapy 15: 767-781.

Gift LJ, Gaughan EM, De Bowes RM and Douglass JP (1992). The influence of intratendinous sodium hyaluronate on tendon healing in horses. Vet. Comp. Orthop. Traumatol. 4: 16-22.

Gossman MR, Rose SJ, Sahrmann SA and Katholi CR (1986). Length and circumference measurements in one-joint and multijoint muscles in rabbits after immobilization. Phys. Ther. 66: 516-520.

Groth GN (2005). Current practice patterns of flexor tendon rehabilitation. J. Hand Ther. 18: 169-174.

Jaakkola JI, Beskin JL, Griffith LH and Cernansky G (2001). Early ankle motion after triple bundle technique repair vs. casting for acute Achilles tendon rupture. Foot Ankle Int. 22: 979-984.

Józsa L, Kvist M, Bálint BJ, Reffy A, et al. (1989). The role of recreational sport activity in Achilles tendon rupture. A clinical, pathoanatomical, and sociological study of 292 cases. Am. J. Sports Med. 17: 338-343.

Józsa L and Kannus P (1997). Human Tendons: Anatomy, Physiology, and Pathology. Human Kinetics, Champaign.

Kannus P and Józsa L (1991). Histopathological changes preceding spontaneous rupture of a tendon. A controlled study of 891 patients. J. Bone Joint Surg. Am. 73: 1507-1525.

Karjalainen T, He M, Chong AK, Lim AY, et al. (2010). Nickel-titanium wire in circumferential suture of a flexor tendon repair: a comparison to polypropylene. J. Hand Surg. Am. 35: 1160-1164.

Khan RJ, Fick D, Keogh A, Crawford J, et al. (2005). Treatment of acute achilles tendon ruptures. A meta-analysis of randomized, controlled trials. J. Bone Joint Surg. Am. 87: 2202-2210. 
Kvist M (1994). Achilles tendon injuries in athletes. Sports Med. 18: 173-201.

Lawrence TM, Woodruff MJ, Aladin A and Davis TR (2005). An assessment of the tensile properties and technical difficulties of two- and four-strand flexor tendon repairs. J. Hand Surg. Br. 30: 294-297.

Mahler F and Fritschy D (1992). Partial and complete ruptures of the Achilles tendon and local corticosteroid injections. Br. J. Sports Med. 26: 7-14.

Martin-Piedra MA, Garzon I, Oliveira AC, Alfonso-Rodriguez CA, et al. (2013). Average cell viability levels of human dental pulp stem cells: an accurate combinatorial index for quality control in tissue engineering. Cytotherapy 15: 507-518.

Martin-Piedra MA, Garzon I, Oliveira AC, Alfonso-Rodriguez CA, et al. (2014). Cell viability and proliferation capability of long-term human dental pulp stem cell cultures. Cytotherapy 16: 266-277.

Mason ML and Allen HS (1941). The rate of healing of tendons: an experimental study of tensile strength. Ann. Surg. 113: 424-459.

Morberg P, Jerre R, Sward L and Karlsson J (1997). Long-term results after surgical management of partial Achilles tendon ruptures. Scand. J. Med. Sci. Sports 7: 299-303.

Mortensen NH and Pedersen B (1990). Wound complications after suturing of Achilles tendon ruptures. Ugeskr. Laeger 152: 3248-3250.

Murphy DJ and Nixon AJ (1997). Biochemical and site-specific effects of insulin-like growth factor I on intrinsic tenocyte activity in equine flexor tendons. Am. J. Vet. Res. 58: 103-109.

O'Broin ES, Earley MJ, Smyth H and Hooper AC (1995). Absorbable sutures in tendon repair. A comparison of PDS with prolene in rabbit tendon repair. J. Hand Surg. Br. 20: 505-508.

Okamoto N, Kushida T, Oe K, Umeda M, et al. (2010). Treating Achilles tendon rupture in rats with bone-marrow-cell transplantation therapy. J. Bone Joint Surg. Am. 92: 2776-2784.

Oliveira RJ, Matuo R, da Silva AF, Matiazi HJ, et al. (2007). Protective effect of beta-glucan extracted from Saccharomyces cerevisiae, against DNA damage and cytotoxicity in wild-type (k1) and repair-deficient (xrs5) CHO cells. Toxicol. In Vitro 21: 41-52.

Ostling O and Johanson KJ (1984). Microelectrophoretic study of radiation-induced DNA damages in individual mammalian cells. Biochem. Biophys. Res. Commun. 123: 291-298.

Reissis Y, García-Gareta E, Korda M, Blunn GW, et al. (2013). The effect of temperature on the viability of human mesenchymal stem cells. Stem. Cell Res. Ther. 4: 139.

Rosenbaum AJ, Wicker JF, Dines JS, Bonasser L, et al. (2010). Histologic stages of healing correlate with restoration of tensile strength in a model of experimental tendon repair. HSS. J. 6: 164-170.

Singh NP, McCoy MT, Tice RR and Schneider EL (1988). A simple technique for quantitation of low levels of DNA damage in individual cells. Exp. Cell Res. 175: 184-191.

Smith AM and Evans DM (2001). Biomechanical assessment of a new type of flexor tendon repair. J. Hand Surg. Br. 26: 217-219.

Soldatis JJ, Goodfellow DB and Wilber JH (1997). End-to-end operative repair of Achilles tendon rupture. Am J Sports Med 25: 90-95.

Thien TB, Becker JH and Theis JC (2004). Rehabilitation after surgery for flexor tendon injuries in the hand. Cochrane. Database. Syst. Rev. CD003979.

Tice RR (1995). The Single Cell Gel/ Comet Assay: a Microgel Eletrophoretic Technique for the Detection of DNA Damage and Repair in Individual Cells. In: Environmental Mutagenesis (Phillips DH and Venitt S, eds.). Bios Scientific Publishers, Oxford, 315-339.

Vailas AC, Tipton CM, Laughlin HL, Tcheng TK, et al. (1978). Physical activity and hypophysectomy on the aerobic capacity of ligaments and tendons. J. Appl. Physiol. Respir. Environ Exerc. Physiol. 44: 542-546.

Vishnubalaji R, Al-Nbaheen M, Kadalmani B, Aldahmash A, et al. (2012). Comparative investigation of the differentiation capability of bone-marrow- and adipose-derived mesenchymal stem cells by qualitative and quantitative analysis. Cell Tissue Res. 347: 419-427.

Winter E, Weise K, Weller S and Ambacher T (1998). Surgical repair of Achilles tendon rupture. Comparison of surgical with conservative treatment. Arch. Orthop. Trauma Surg. 117: 364-367.

Young RG, Butler DL, Weber W, Caplan AI, et al. (1998). Use of mesenchymal stem cells in a collagen matrix for Achilles tendon repair. J. Orthop. Res. 16: 406-413. 